\title{
Carbon Monoxide Poisoning due to Gas Water Heater
}

\author{
Bidesh Bista*1, Dhiraj Manandhar², Rupesh Mishra1, Pradeep Shrestha1, Alok Dhungel1 \\ Civil Service Hospital, Kathmandu, Nepal
}

${ }^{1}$ Department of Medicine, Civil service hospital, Min Bhawan, Kathmandu, Nepal

${ }^{2}$ Department of Medicine, Nepal Medical College, Jorpati, Kathmandu, Nepal

\begin{abstract}
Background and Objectives: Carbon Monoxide (CO) poisoning is a leading cause of injury and death due to poisoning in many parts of the world. Among numerous sources of CO, the gas water heater can be a potential under looked source causing an accidental Carbon monoxide poisoning. In the perspective of Kathmandu valley, where there are houses with small bathrooms, inadequate ventilation and absent $\mathrm{CO}$ detectors, gas water heaters can be extremely dangerous even if it liberates small amount of $\mathrm{CO}$ gas. Herein, we present a case of CO poisoning to increase awareness about the gas water heater use and the possible risk of $\mathrm{CO}$ poisoning in our community.

Presentation of Case: A 34 years old healthy female from Patan, presented with the history of loss of consciousness for 15 minute while taking bath on a gas water heater. There was no spontaneous respiration, no cardiac activity and her body temperature was below normal.

Discussion: CO is toxic to all aerobic forms to life. CO binds to hemoglobin 230 times faster than oxygen causing cellular hypoxic damage and death. CO poisoning is not uncommon in our society and many such cases are misdiagnosed for some other illness.

Conclusion: Use of the gas water heaters and likelihood of CO poisoning should be notified as a public concern. People need to be aware of these hazards to prevent fatal events and likely death due to exploitation of gas water heaters.

Key words: Carbon Monoxide, Gas, Heater, Water

\section{INTRODUCTION}

Carbon Monoxide poisoning appears to be the leading cause of death due to poisoning worldwide [1]. The gas water heater can be a potential under looked source of the accidental Carbon monoxide poisoning in our

society. It is a common appliance used in our country for the purpose of bathing and other house hold tasks. It contains a gas burner and a sealed combustion chamber of the heating appliance, which generates carbon monoxide (CO), hydrocarbons and nitric oxide [2]. The manufacturers of the gas water heater claim
\end{abstract}


that only small percentage of $\mathrm{CO}$ is liberated from the combustion fuel. However, the faulty heater may generate more of $\mathrm{CO}$. In the context of Kathmandu valley, where there are houses with small bathrooms, inadequate ventilation and absent $\mathrm{CO}$ detectors, even a small percentage of $\mathrm{CO}$ liberated from the gas water heater can be extremely dangerous. Herein, we present a case of $\mathrm{CO}$ poisoning to increase awareness about the gas water heater use and possible risk of $\mathrm{CO}$ poisoning in our community.

\section{CASE REPORT}

A 34 years old healthy female from Patan presented to us with the history of loss of consciousness for 15 minute, while taking bath on a gas water heater. There was no spontaneous respiration, no cardiac activity and her body temperature was below normal. She was immediately resuscitated after which she gained her cardiac activity and was transferred to the Intensive Care Unit (ICU). Her pupils were dilated and did not react to the light (acknowledging the drugs given during resuscitation). Her corneal reflexes and dolls eye reflexes were absent. The Computerized Tomography (CT) scan of her head showed diffuse cerebral edema, suggested severe hypoxic brain damage. Her chest X-ray was suggestive of Acute Respiratory Distress Syndrome (ARDS). Her Arterial Blood Gas (ABG) analysis showed metabolic acidosis of $\mathrm{pH} 7.1$ and bicarbonate level of $16 \mathrm{mmol}$ (acknowledging CPR). She died after 32 hours in the ICU.

In order to find the etiology of her life taking event, her family members were questioned. An interesting fact revealed that the family members of the deceased also reported to have feeling of lightheadedness and shortness of breath while using the gas water heater during shower. We were unable to measure the CO level in the deceased patient and their family members as the laboratory tests needed to detect $\mathrm{CO}$ Poisoning were not available at our center.

\section{DISCUSSION}

CO is a colourless, odorless, tasteless and non-irritant gas produced through incomplete combustion of organic matter [3]. $\mathrm{CO}$ is a toxic gas and can avidly bind to the hemoglobin $(\mathrm{Hb})$ with an affinity approximately 230 times that of the oxygento form carboxyhemoglobin (CO-Hb) [4,5]. Increased affinity between $\mathrm{Hb}$ and oxygen during CO poisoning causes hypoxic tissue injury. CO is toxic to all aerobic forms of life [6]. In Industrial countries, $\mathrm{CO}$ is responsible for more than $50 \%$ of death due to the poisoning [7].

Fatal cases of $\mathrm{CO}$ poisoning are grossly under reported or misdiagnosed by the medical professionals. Incidence of $\mathrm{CO}$ poisoning in Nepal is unknown, since many non-lethal exposures go unnoticed and hundreds of death are suspected to be due to CO poisoning in the remote areas by using traditional fire wood stoves to keep unventilated rooms warm during the winter seasons. Recently, gas water heaters are becoming a threat for $\mathrm{CO}$ poisoning in the urban areas of Nepal. This was not the first case we know of an accident while taking shower in the gas water heater. Similar cases have occurred in the past with loss of consciousness while taking shower in a gas water heater. Some patients have presented with hypoxic changes in brain but were fortunate to be alive (Personal communication with a doctor of another local hospital in Kathmandu). We have also encountered increased number of seizure 
attacks in the patients with epilepsy while taking shower in a gas water heater, most likely due to hypoxia.

CO poisoning from gas water heaters are infrequent but can be fatal. 17 cases of nonfatal and two cases of fatal CO poisoning in bathrooms were reported in the Cameron Highlands Hospital from 1988 to 1995 by Chong CK et al [8]. A study in Denmark showed increased production of $\mathrm{CO}$ from gas water heaters when installation maintenance checks were not done or was carried out unprofessionally [9]. Breindl D and Pollak S reported two suicidal deaths, deriving from the exhaust fumes of two different gas water heaters [10].

CO is a common pollutant found in the atmosphere. On an average, exposure of more than 100 ppm (i.e for every 999,900 molecules of air, 100 molecules of $\mathrm{CO}$ ) is hazardous to the human health [11]. In a closed space like bathroom, concentration of CO can easily build up to the dangerous level. CO poisoning should be suspected in any person with severe headache, acutely altered mental status especially during cold weather, when improperly vented gas water heating system is used [12].

\section{CONCLUSION}

Use of the gas water heaters and likelihood of CO poisoning should be notified as a public concern. Public awareness and education on safe use of the gas water heater has to be emphasized. Gas water heaters must not be used in any bathroom with poor ventilation. If possible, CO detector with alarm system has to be installed in the bathroom with the gas water heater. The gas water heater must be kept on proper working condition. Thus, the little awareness can prevent fatal events.

\section{ACKNOWLEDGEMENT}

Authors would like to thank Department of Medicine, Civil service hospital, Min Bhawan, Kathmandu, Nepal for their contribution in this case study.

\section{AUTHOR'S CONTRIBUTION}

BB, DM, RM, PS, AD- were involved in writing the entire article and did all the literature review. All authors read, finalised and approved the article.

SOURCE OF SUPPORT: Logistic Support by Civil service hospital, Kathmandu, Nepal.

CONFLICT OF INTEREST: Authors declared that there is no conflict of interest regarding the publication of this paper.

\section{REFERENCES}

1. Thom SR. Hyperbaric-oxygen therapy for acute carbon monoxide poisoning. The New England Journal of Med 2002;347(14):1105-6.

2. Bob Formisano. Troubleshooting a tank type water heater. http//www.About.com. Patent 5791298

3. Bateman DN. Carbon Monoxide. Medicine 2003; 31(10):233.

4. Raub, JA, Benignus VA. Carbon Monoxide and the Nervous System. Neuroscience and Biobehavioral Rev 2002;26(8):925-40.

5. Townsend CL, Maynard RL. Effects on health of prolonged exposure to low concentrations of carbon monoxide. Occupational and Environmental Med 2002;59(10): 708-11.

6. Haldane J. The action of carbonic oxide on man. The Journal of Physiol 1895; 18: 430-62.

7. Omaye ST. Metabolic modulation of carbon monoxide toxicity. Toxicol 2002; 180 (2): 13950 .

8. Chong CK, Senan P, Kumar GV. Carbon monoxide poisoning from gas water heater installed and operated in the bathroom. Med J Malaysia 1997;52(2):169-71.

9. Thomsen JL, Kardel T. Intoxication at home due to carbon monoxide production from gas 
water heaters. Forensic Sci Int 1988 ;36(12):69-72.

10. Breindl D, Pollak S.A gas water heater as a means of suicide. BeitrGerichtl Med. 1989;47:649-55

11. Prockop LD, Chichkova RI. Carbon monoxide intoxication: an updated review. Journal of the Neurological Sciences 2007 NOV;262(12):122-30

12. Donald Simpson, Bathroom gas water heaters and the risk of carbon monoxide poisoning, Health Education Journal, 1973;32(4):120-4

Correspondence to:

Dr. Bidesh Bista

Department of Medicine, Civil service hospital, Min Bhawan, Kathmandu, Nepal

Email: bideshbista@hotmail.com 